\title{
Технологии управления процессом обучения спортивным упражнениям, сложным по координации
}

\section{Виктор Болобан}

$$
\text { Бердянский государственный педагогический университет, Бердянск, Украина }
$$

Анотація. У статті представлено технології управління навчанням спортивних вправ, виходячи із вимог до розвитку їх важкості у видах спорту, складних за координацією. Технології побудовані на знанні, врахуванні й використанні механізмів, що управляють іррадіацією, концентрацією і стабілізацією процесів збудження і гальмування у центральній нервовій системі. Вони реалізуються на основі біомеханічного дослідження структурного складу спортивних вправ, психологічних параметрів і індивідуальних показників спортивної підготовленості спортсменів, впливу полідисциплінарного змісту навчання спортивних вправ. Мета. Розробити й обгрунтувати окремі актуальні технології управління процесом навчання спортивних вправ зі складною координацією структури рухів. Методи. Аналіз даних науково-методичної літератури, мережі Інтернет, педагогічне спостереження, аналіз протоколів змагань. Результати. Вивчено алгоритми використання біологічного зворотного зв'язку як сучасного методу самоконтролю, а також запропоновано практичні рекомендаціі тренерам і спортсменам у процесі навчання спортивних вправ. Установлено, що біологічний зворотний зв'язок реалізується на основі і в поєднанні з трансфрерною технологією, лінійно розгалуженим програмуванням навчального матеріалу з урахуванням індивідуальних показників спортивної підготовленості тих, хто займається. Вони дозволяють ефективно формувати знання, рухові уміння і навички в процесі навчання базових, складних і високої трудності вправ.

Ключові слова: спортивні вправи, технологія, управління, структура, координація, рухові уміння, навички, технічна підготовленість.

\section{Viktor Boloban}

\section{TECHNOLOGIES OF MANAGING THE PROCESS OF TRAINING COORDINATION COMPLEX SPORTS EXERCISES}

Abstract. The article presents the technologies of managing the training of sports exercises, based on the requirements for the development of their difficulty in complex coordination sports events. Technologies are based on knowledge, consideration and use of mechanisms that control the irradiation, concentration and stabilization of excitation and inhibition processes in the central nervous system. They are implemented on the basis of biomechanical study of the structural composition of sports exercises, psychological parameters and individual indices of sports fitness of athletes, the impact of multidisciplinary content of sports exercise training. Objective. To develop and substantiate some current technologies for managing the process of learning sports exercises with complex coordination of the motion structure. Methods. Analysis of data of scientific and methodical literature, Internet, pedagogical observation, analysis of competition protocols. Results. Algorithms for using biological feedback as a modern method of self-control have been studied, practical recommendations for coaches and athletes in the process of learning sports exercises have been suggested. It is established that biological feedback is realized on the basis of and in combination with transfer technology, linearly branched programming of educational material taking into account individual indices of sports fitness of those engaged. They allow efficient development of knowledge, motor skills and abilities in the process of learning basic, complex and high difficulty exercises.

Keywords: sports exercises, technology, management, structure, coordination, motor skills, technical fitness.
Болобан В. Технологии управления процессом обучения спортивным упражнениям, сложным по координации. Теорія і методика фрізичного виховання і спорту. 2020; 2: 23-35 DOI: 10.32652/tmfvs.2020.2.23-35
Введение. Основная задача обучения спортивным упражнениям заключается в обогащении занимающихся необходимыми знаниями, двигательными умениями и навыками, оказании помощи в познании окружающего мира и, главным образом, самих себя, своих способностей и развитие их. Знание о спортивном упражнении - это субъективный образ, представление о нем, отражение его сущности в сознании обучаемых лиц. Характеризуется тем, что обучаемый воспроизводит его в идеальной фрорме в виде словесного терминологически правильного изложения, описания, изображения на рисунке, схеме [31]. Далее следует знание о нем в действии - умение выполнять спортивное упражнение: способность занимающихся управлять входящими в него движениями на основе знаний техники, опыта, фризической (двигательной), психологической подготовленности.

Отметим, что нет вида спорта, занятия которым не начинались бы именно с обучения, где технически верно поставленное движение, ссрормированное как навык, не играло бы решающей роли. Обучение - крайне трудный процесс, он нередко подменяется установками на выполнение большого объёма работы на всех этапах подготовки спортсменов. Два, а то и три занятия в день не оставляют спортсмену времени на полноценный отдых, образование, для семейных отношений.

Особенно печально, когда в такой процесс вовлечены дети. Поэтому задачи обучения, которые при более вдумчивой работе порой решаются в считанных попытках исполнения, чаще всего реализуются через изнурительную работу, после чего требуется лечение, восстановление и др. [9]. Анализ монографий, книг, статей, учебников, другой научнометодической литературы послед- 
них лет свидетельствует о том, что в них содержится недостаточно результатов исследований обучения двигательным действиям. Между тем, проблема обучения спортивным упражнениям, особенно сложным, проблема совершенствования методологии и современных технологий формирования двигательных умений и навыков стоит как никогда остро и актуально в связи с бурным прогрессом олимпийского спорта. Уместно в этой связи обратиться к литературным источникам прошлых лет, когда строились теории, методологии и практики обучения двигательным действиям, и прежде всего к гениальному труду Яна Амоса Коменского «Великая Дидактика» [14]. Теоретико-методические рекомендации следовать в процессе обучения «от простого к сложному, от легкого к трудному», изложенные в главе «Основы легкости обучения и учения», являются актуальными и в настоящее время, потому что неоправданно убыстряется темп подготовки детей и подростков в олимпийских чемпионов [23].

Дальнейшее развитие педагогической мысли продолжает укреплять научные положения о том, что процесс обучения должен соотноситься исключительно с возможностями занимающихся: умственными, фризическими, психическими, функциональными. Это подтверждается теорией развивающего обучения А. Н. Леонтьева [18], которая направлена на исследование содержания, методов и сорм, ориентирующих на всестороннее развитие фризических, познавательных и нравственных способностей занимающихся путем использования закономерностей индивидуального развития и их потенциальных возможностей. Знания, констатирующие данный учебный предмет или его разделы, занимающиеся осваивают благодаря знанию их первооснов (происхождения).

Согласно теории П. Я. Гальперина [10], в ходе деятельности приобретается ориентировочная основа действия, т. е. система представлений о цели, плане, средствах осуществления предстоящего выполняемого задания. Чтобы выполнить действие, нуж- но знать, что при этом произойдет и на каких аспектах происходящего будет сконцентрировано внимание, что позволит не выпустить желаемые изменения из-под контроля. Психологопедагогические исследования в спорте основаны на теории П. Я. Гальперина о планомерно-поэтапном формировании действий и проблеме ее переноса на моторное обучение.

Ведущую роль в современном олимпийском спорте играет теория обучения спортивным упражнениям со сложной координационной структурой движений, разработанная теоретиками гимнастики [8, 25, 31, 33 36]. В своих исследованиях ученые выделили следующие ведущие элементы структуры процесса обучения упражнениям в спорте высших достижений: подготовка к освоению нового упражнения, формирование двигательных представлений, углубленное разучивание упражнения, введение в эксплуатацию, эксплуатация, совершенствование и модернизация навыка, эксплуатационные трансформации - категория изменений двигательного навыка, амортизация и прекращение эксплуатации.

Выдвинутая теория обучения согласуется с теорией формирования двигательного навыка профессора А. Н. Крестовникова [17], который выделил три фразы: первая - объединение отдельных частей в двигательное действие. Образование условно-рефлекторных связей при широком распространении (иррадиации) возбудительных процессов по коре головного мозга. У высококвалифицированных спортсменов фаза иррадиации может быть не выражена вторая - устранение «лишних» деталей движения. Концентрация нервных процессов с постепенным ограничением возбуждения; третья - совершенствование движения. Стабилизация (автоматизация) нервных процессов. Сначала простые, а затем и сложные компоненты движения начинают выполняться на более низких фоновых уровнях построения движения. Устранение вспомогательных движений из зоны внимания называется автоматизацией движения.
Спортивные упражнения представляют разную трудность. При их овладении и демонстрации на соревнованиях спортсмену необходимо проявлять эмоциональную устойчивость, а в ряде случаев даже идти на риск; двигательная и специальная техническая подготовленность, сенсомоторная координация, внимание, моторная память на движения, эмоциональная устойчивость, решительность и смелость являются основой технической подготовки и подготовленности [7, 9, 25, 32, 36, 39].

Эфффективная работа по освоению нового для спортсмена упражнения может быть начата и продуктивно осуществляться только при ее соответствии ряду исходных условий и специфических особенностей формирования двигательных навыков в спорте; многие упражнения для занимающихся являются новыми, необычными и незнакомыми им по предшествующему двигательному опыту. Обучение упражнениям связано с требованием выполнить движения в условиях и стиле, предписанном Правилами соревнований; двигательные навыки в спорте должны обладать высокой устойчивостью и стабильностью при выполнении трудных упражнений в изменяющихся условиях внешней среды и внутреннего состояния спортсмена [4, 8, 15, 20, 32]. Теория опережающего обучения [13] послужила методологической основой для выведения из ее содержания принципа трудности, в котором заложены научно-методические положения, полученные экспериментальным путем, а именно: «В обучении спортивным упражнениям следовать от легкого к трудному, а при созданной у занимающегося добротной двигательной, технической и психологической базе - от трудного к ещё более трудному (решение сверхзадачи) или от трудного к простому» [4].

Профрессор Пабло Челник [21] указывает, что для быстрого и прочного освоения нового навыка следует вносить в тренировочный процесс небольшие изменения (для приобретения нового опыта важно качество практических упражнений, а не их ко- 
личество). Объясняет это тем, что во время процесса обучения, при внесении небольших и достаточно тонких изменений, сохраняется активность головного мозга, сокращается время оперативного мышления, что способствует получению эффрективного конечного результата. Подразумевается, что это осуществляется благодаря «перезакреплению» двигательного навыка, что приводит к возрождению и смене существующих воспоминаний под влиянием новых знаний. Утверждается, что при тренировке измененной версии навыка результат придет гораздо быстрее, чем при постоянном повторении одного и того же.

Следуя теории «перезакрепления» двигательного навыка при построении соревновательных композиций для юных спортсменок, занимающихся художественной гимнастикой, на этапе специализированной базовой подготовки, тренер Я. О. Коваленко формировала двигательные навыки, внося в программу следующие изменения и дополнения: а) гимнастками выполнялись упражнения с мячом, обручем, лентами, булавами, которые имели различные размеры, вес, цвет; б) выполнялись акробатические упражнения с поддержкой (физическая проводка по движению с различной степенью усилий при поддержке одна другой); в) изменялся темп и ритм выполняемых упражнений с предметами и без предметов; г) выполнялись броски и каты предметов на разную высоту и длину.

В соответствии с теорией П. Фресса, Ж. Пиаже [35], сенсомоторное мышление является основой двигательного навыка. Решаются двигательные задания через алгоритмы пошагового использования элементов дидактики, включая различные техники и технологии. В частности, в современном научно-практическом мире принято «думать двигательным центром». Если одному специалисту необходимо передать другому некую мысль, то наиболее удобным способом чаще всего представляется рисование на доске, листе бумаги, планшете. Можно говорить о том, что тренер передает спортсмену мысль (инсормацию) через двигательные действия для формирования оперативного мышления. Оперативное мышление (смысловая структура движения - $[3,29])$, строится на уже сфрормованных умениях и навыках двигательных действий, а также обеспечивается всесторонним развитием и совершенствованием сенсомоторной координации и является основой технической подготовленности [7, 8, 11, 19, 33].

Цель исследования - разработать и обосновать отдельные актуальные технологии управления процессом обучения спортивным упражнениям со сложной координационной структурой движений как концепцию повышения уровня технической подготовки и подготовленности спортсменов.

Методы исследования: анализ данных научно-методической литературы, сети Интернет, педагогическое наблюдение за процессом и результатами проведения учебно-тренировочных занятий и спортивных соревнований, анализ протоколов соревнований квалифицированных спортсменов, дневников тренеров и занимающихся, видеоанализ, сравнение аналогия, беседа, анкетирование, экспертная оценка, педагогический эксперимент, оптико-электронные методы исследования, стабилографрия, математическая статистика. Также использовались термины, характеризующие процесс обучения.

Алгоритм - система последовательных операций, совокупность последовательных шагов, схема действий, точно предписывающих, как и в какой последовательности будет выполнено решение двигательных и других задач, приводящих к желаемому результату.

Двигательная задача - вербальномоторное указание, система указаний, инструкция на то, что субъект должен сделать в данной ситуации посредством двигательной активности, в которой на основе образа движения, соотнесены цели движения, способы и средства [15].

Двигательные навыки - приобретенная способность владения техникой двигательного действия, которая характеризуется автоматизированным (при разном по степени контро- ле со стороны сознания) управлением движениями, высокой точностью и надежностью исполнения [3, 8, 20, 23].

Двигательные умения - приобретаемая способность овладения двигательным действием, которая характеризуется сознательным управлением движением, неустойчивостью к действию сбивающих фракторов, нестабильностью результатов выполнения движения.

Концепция (лат. conceptio - система понимания) - систематизация идей (взглядов), выработанных для понимания направления развития.

Обучение - целенаправленный процесс передачи ученику необходимых знаний и выработки у него необходимых умений и навыков [8].

Полидисциплинарность - способ расширения научного мировоззрения, заключающийся в рассмотрении того или иного явления, не ограничиваясь рамками какой-либо одной научной дисциплины.

Программирование - процесс составления упорядоченной последовательности программы действий. Дидактическое программирование процесс переработки учебного материала для программированного обучения: линейное программирование, линейно-разветвленное, адаптивное (компьютерное - высшая форма программирования). Работа тренера не всегда обеспечена необходимым инструментарием. В этих условиях программированное обучение является средством, повышающим научно-методический уровень работы тренера, спортивные достижения занимающихся [8].

Структура - в теории управления рассматривается как внутреннее единство содержания [2]. Это сложившиеся определяющие закономерности взаимодействий упорядоченных компонентов системы движений (подсистем и их элементов). Определяет течение внутренних процессов, взаимодействие с внешним окружением, появление новых свойств и возможности развития системы [11].

Технология (греч. techne-процесс, искусство, мастерство, logos- слово, учение, наука) - системный ме- 


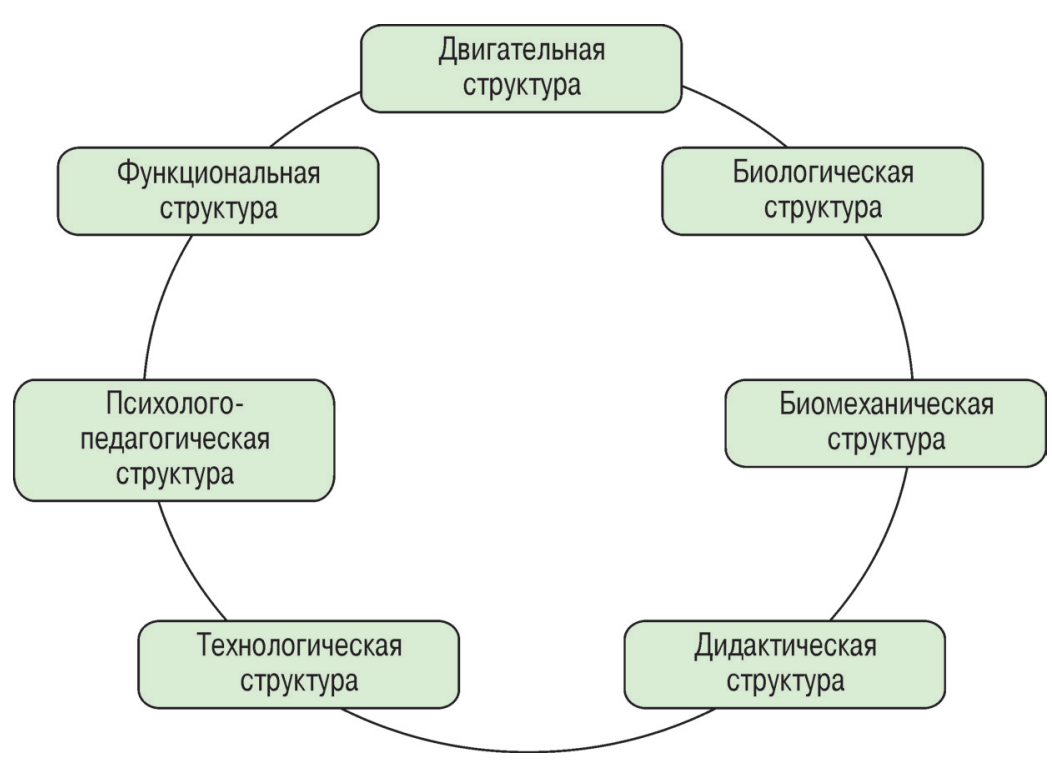

Рисунок 1 - Примерный структурный состав спортивного упражнения

тод создания, применения и определения процесса преподавания и учения; совокупность психолого-педагогических установок; организационнометодический инструментарий педагогического процесса. 0 технологизации образования писал Я. А. Коменский [14]. Он выделял умение правильно определять цель, выбирать средства ее достижения, формировать правила пользования этими средствами. Технология обучения - это цепочка действий и операций, направленных и ориентированных на результат.

Результаты исследования и их обсуждение. Изучены и представлены актуальные технологии обучения спортивным упражнениям и их примерные дидактические алгоритмы для использования в учебно-тренировочном процессе в видах спорта, сложных по координации.

Структурный состав спортивно го упражнения, подлежащего обучению. В исследовании решалась задача разработать структурный состава спортивного упражнения, подлежащего обучению. Основой для разработки структурного состава спортивного упражнения послужила теория чисел [22]. Хорошо известно, что число в математике имеет структурный состав. Например, состав числа 4 - это: $2+2,3+1,1+1+1+1$, $0+4$ или любого другого числа. Професссор 0. Оре пишет, что выдающие- ся достижения в науке и технике возможны при использовании теории чисел. Состав числа играет ффундаментальную роль для получения нового знания, для решения технической задачи, разработки проектов, технологий реализации. Теория чисел - часть математики, посвященная изучению свойств целых чисел и их обобщений. Как свидетельствует анализ проблемы обучения двигательным действиям [37], спортивное упражнение содержит примерный структурный состав: двигательную структуру, биологическую, биомеханическую, дидактическую, технологическую, психолого-педагогическую, функциональную (рис. 1).

Примерный структурный состав спортивного упражнения позволяет эфрфективно выстраивать алгоритм полидисциплинарного формирования знаний, двигательных умений и навыков для качественного обучения и по следующей спортивной подготовки.

Двигательная структура спортивного упражнения. Представим на примере сложного гимнастического элемента на бревне , выполненного абсолютной чемпионкой Игр XXIX Олимпиады Настей Люкин (США), колпинского переворота (прыжок вверх-назад с поворотом на $180^{\circ}$ в полете-переворот вперед с поочередной постановкой рук и ног на опору). Для выполнения этого переворота спортсменка должна владеть скоростно-сило- выми возможностями (прыгучестью), координировать толчок ногами с махом рук при отталкивании и технически точным входом в поворот в полете на $180^{\circ}$ движениями пояса верхних конечностей и бедер (координированность движений), соответствующим требованиям к технике поворотом с прямым и последовательно прогнутым положением тела (регуляция позы тела, гибкость, подвижность), эфрфективно выполнять вращение (ориентирование в пространстве), сохранять статодинамическую устойчивость при перемещении по бревну с поочередной постановкой рук и ног на опору (регуляция позы тела). Пример показывает, что тренеру необходимо предметно знать технику вида спорта, владеть современными технологиями обучения и подготовки; спортсменке - иметь соответствующую требованиям двигательную подготовленность (прыгучесть, ловкость, координированность движений, гибкость, подвижность, ориентировку в пространстве, регуляцию позы, устойчивость); демонстрировать базовый уровень спортивной техники упражнения. Двигательная структура спортивного упражнения - это общесизический, специально-физический, специально-технический, фрунциональный состав упражнения, который потребуется спортсменке, или, другими словами, который будет предъявлен гимнастке в виде специального требования и которым она должна владеть. Чтобы освоить колпинский переворот на бревне, необходимо быть двигательно и технически подготовленной, ориентироваться во времени и пространстве, психически устойчивой, четко дифференцировать прилагаемые усилия. Фактически речь идет об арсенале движений, которым должна владеть гимнастка для успешного освоения упражнения.

Биологическая структура спортивного упражнения. При освоении колпинского переворота на бревне у спортсменки последовательно формируются двигательные представления, умения и навыки целесообразных двигательных действий, которые реализуются на основе происходящих биологических процессов - ирради- 
ации, концентрации и стабилизации возбуждения и торможения в центральной нервной системе при четко сбалансированных функциях управления и контроля сознания и подсознания за процессом обучения [17, 20, 23].

Биомеханическая структура спортивного упражнения характеризуется составом параметров и значением статических, кинематических и динамических характеристик действий движений (скорость, ускорение, суставные углы, траектории движений звеньев тела), а также их взаимосвязями, необходимыми для его выполнения. В данном примере важно, чтобы у спортсменки был сформирован двигательный навык владения узловыми элементами техники колпинского переворота в фразовой структуре упражнения: пусковой позой тела (оптимальным положением тела, при котором возможен точный, оптимальный и двигательно-дозированный от вертикали прыжок вверх-назад, для придания телу вращающего момента вокруг фрронтальной и продольной осей), мультипликацией позы выпрямившись-прогнувшись (технически правильным расположением биозвеньев в схеме тела (суставные углы) и системе координат, необходимыми скоростями и ускорениями), итоговой позой тела (статодинамической устойчивостью) $[6,8,11,19,39]$.

Дидактическая структура спортивного упражнения. На прочном фундаменте содержания биомеханики строится надежная дидактическая база, основой которой должны стать принципы: индивидуализации, сопряженного воздействия, прочности, доступной трудности; методы, активизирующие процесс обучения: практический, проблемный, моделирования, программирования; подводящие, подготовительные, имитационные упражнения; технические средства (поролоновые маты и приспособления из них для обучения, система бревен различной высоты и др.); элементы регламентации, контроля и коррекции [7].

Технологическая структура спортивного упражнения. Управляемый процесс обучения предусматривает использование четко выстроенного алгоритма линейно разветвленного программирования учебного материала, отдельных компонентов трансферной технологии и опережающего обучения; контрольным инструментом процесса обучения должна стать биологическая обратная связь (преимущественно зрительно-моторная, вербально-моторная, моторно-моторная, вестибуло-моторная) [27-29, 37].

Психолого-педагогическая структура спортивного упражнения должна характеризоваться осмысленностью двигательных действий и развитой памятью на движения, двигательным представлением о разучиваемом упражнении, идеомоторным компонентом действия - движения, качествами личности (трудолюбие, творчество, организованность), свойствами нервной системы (динамичная, сильная, сбалансированная), решительностью, смелостью. Структурными составляющими являются индивидуальные особенности нервно-психических процессов - автоматизированным движением становится такое движение, в котором двигательная часть упражнения управляется низшими отделами центральной нервной системы (ЦНС), а смысловая - высшими [1, 3, 17, 20, 23, 29]; индивидуальная двигательная и техническая подготовленность.

Функциональная структура спортивного упражнения характеризуется тем, что в спортивной технике колпинского переворота, выполняемого спортсменкой, основные управляющие воздействия - это мышечные усилия, которые определяются совокупностью морфологических и фрункциональных возможностей: сенсомоторной координацией с приоритетным функционированием вестибулярной сенсорной системы, ловкостью, механизмами регуляции позы тела, скоростно-силовыми показателями [3, 6, 31, 39]. В процессе обучения упражнениям различной координационной трудности необходима интеграция структурного состава спортивных упражнений при ведущей роли одних либо других структур.
Полидисциплинарное формирование двигательных представлений, двигательных умений и навыков. На основе теоретических знаний $[1,3,9$, 17, 20, 23, 27] и практического опыта $[5,8,12,25,33,37]$ разработана технология полидисциплинарного формирования двигательных представлений, двигательных умений и навыков в процессе обучения спортивным упражнениям, сложным по координации, в структуре многолетней подготовки спортсменов.

Полидисциплинарные особенности развития двигательных представлений, формирование двигательных умений: а) биологические - иррадиация возбуждения и торможения и их распространение в ЦНС; при этом, в большей степени иррадиации подвергается возбуждение, так как возбуждающих интернейронов больше, чем тормозных; б) биомеханические - скованность и неточность движений, дискоординация мышечных усилий, нарушение пространственных и временных параметров движений, отсутствие слитности движений, неустойчивый темпо-ритм; неоправданно активное участие в выполнении движений высших отделов ЦНС, вызванное иррадиацией процессов возбуждения и торможения; в) психолого-педагогические - использование подводящих упражнений, детализированных, упрощённых; используются подводящие упражнения постепенного нарастания сложности (для этого необходимы способы и приемы, например, обучение в руках тренера, проводка по движению).

Полидисциплинарные особенности углубленного формирования двигательного навыка: а) биологические - развитие концентрации процессов возбуждения и торможения в ЦНС (после иррадиации возбуждение и торможение конвергируют, т.е. сходятся к одним и тем же группам нервных клеток ЦНС); б) биомеханические - уменьшение мышечной скованности при выполнении движений, улучшение координации движений отдельных звеньев тела по амплитуде, мышечным усилиям и времени; приобретение необходимого темпо-ритма движений; повыше- 
A

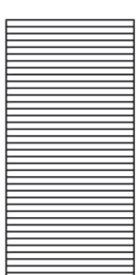

1

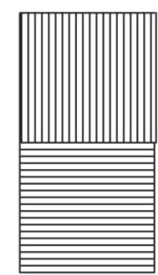

2

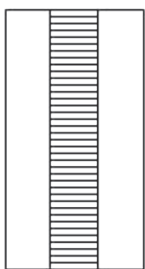

3

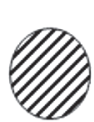

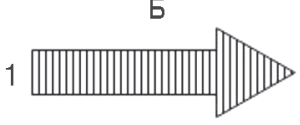

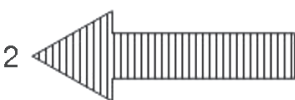

3
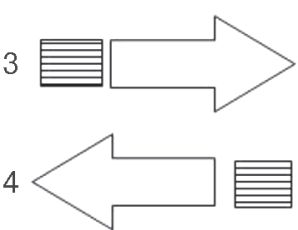

Рисунок 2 - Методические приемы совершенствования двигательногонавыка в процессе выполнения спортивного упражнения:

А - выполнение упражнения: 1 - в целом, 2 - по частям, 3 - обучение управляющему движению; Б - последовательность выполнения упражнения: 1 - прямая, 2 - обратная, 3 - прямая дискретная, 4 - обратная дискретная; В - выполнение подводящих упражнений: «щадящего» и «напряжённого» характера в соотношении $0: 4$

ние качества двигательного взаимодействия в системах; передача управления деталями спортивной техники движений на нижележащие уровни ЦНС; непостоянный контроль сознания за выполнением упражнения; в) психолого-педагогические - условия, в которых осуществляется процесс обучения приближаются к соревновательным. Соотношение подводящих упражнений «щадящего» характера и «напряженного» равно 1:3. Вместе с тем имеется слабая устойчивость ЦНС к различного рода помехам, а также большим тренировочным нагрузкам и стрессу.

Полидисциплинарные особенности совершенствования двигательного навыка: а) биологические - согласованная работа мотонейронов, стабилизация процессов возбуждения и торможения в ЦНС; формирование последовательной и взаимной индукции очагов возбуждения и торможения в ЦНС; б) биомеханические - статические, кинематические, динамические параметры выполняемых упражнений и их показатели соответствуют канонам спортивной техники или близки к ним; становится совершеннее процесс распределения функций в ЦНС, достигается ав- томатизация выполняемых упражнений, обеспечивается подвижность двигательного навыка, позволяющая спортсмену в процессе обучения выходить на новые, более совершенные умения и навыки, достигая, таким образом, мастерства в движениях; в) психолого-педагогические - интенсификация процесса обучения, формирование индивидуального стиля спортивной техники, активизация творческой поисковой деятельности совершенствование обратной связи в обучении, т.е. установление положительной ответной реакции занимающихся на педагогические процессь реализации программ обучения; достижение высокого уровня межличностных отношений, сотрудничества; рост спортивно-технического мастерства. Варианты, последовательность и напряжённость обучения направлены на совершенствование спортивного упражнения в целом. При этом важное место отводится дальнейшей проработке узловых элементов спортивной техники, приобретение нового качества исполнительского мастерства. В процессе обучения соотношение подводящих упражнений «щадящего» характера и с «напряжением» соотносится как $0: 4$ (рис. 2).
Процесс совершенствования двигательных навыков тренер и занимающийся строят на основе главной и конкретных целей тренировочных занятий, задач и планов соревновательной деятельности. Для совершенствования выученных сложнокоординационных упражнений в разных видах спорта необходимо реализовать тренировочные формы соревновательных упражнений: выполнять упражнения в условиях вестибулярной нагрузки, с ограниченным зрительным контролем, при изменении исходного и конечного положений, на возвышении, подвижной, зауженной опорах, с партнёром, при переходе от динамики к статике и наоборот, в сложных спортивных соединениях упражнений, при утомлении, в условиях, приближенных к соревновательным.

Узловые элементы спортивной техники как позные ориентиры движений в фазовой структуре упражнения. Технология обучения узловым элементам спортивной техники в фразовой структуре упражнения реализуется с использованием метода позных ориентиров движений [6, 14, 19, 21, 37, 39]. Метод позных ориентиров движений предназначен для биомеханического анализа спортивной техники упражнения и оценки показателей предшествующих и последующих поз тела, положений тела с идентификацией узловых элементов спортивной техники в его фазовой структуре (рис. 3).

При биомеханическом анализе акробатических прыжков на дорожке, упражнений спортивной гимнастики, художественной гимнастики, прыжков на батуте, прыжков в воду идентифрицированы такие узловые элементы: в фазе подготовительных двигательных действий - пусковая поза (ПП) тела (биомеханически рациональная поза тела для входа в основ-

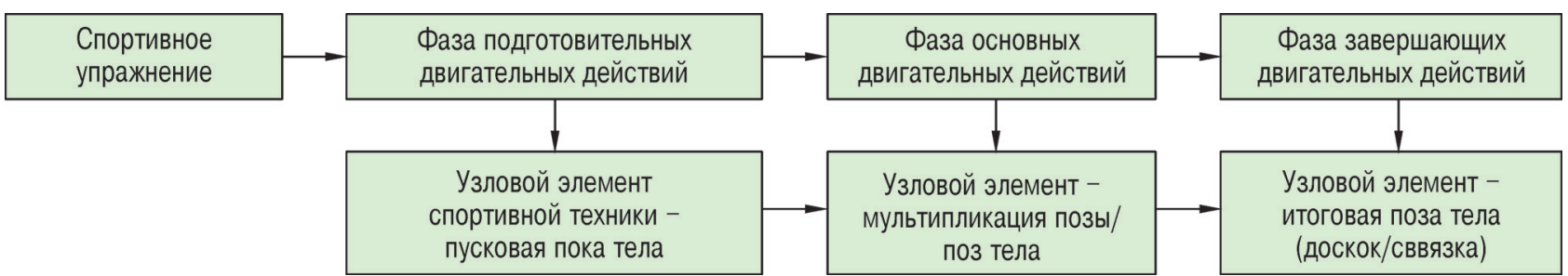

Рисунок 3 - Узловые элементы спортивной техники в фазовой структуре спортивного упражнения 
ную фразу упражнения); в фазе основных двигательных действий - узловой элемент - мультипликация позы/поз тела (мультипликация позы/поз (МП) тела как узловой элемент спортивной техники рассматривается как процесс последовательного выполнения мгновенных фиккированных позы/поз однопрофиильного, например, двойное сальто назад прогнувшись или комбинированного профиля движений, например, двойное сальто назад прогнувшись с поворотом на $360^{\circ}$ в первом сальто для создания целостного двигательного действия с контролируемой сменой поз и положений тела; МП определяет состав и структуру упражнения); в фазе завершающих двигательных действий - узло вой элемент итоговая поза (ИП) тела, характеризует устойчивость тела на опоре в интересах завершения упражнения - доскок или создание условий для выполнения биомеханического рационального перехода к последующему движению - упражнению. На основе знания спортивной техники узловых элементов представляется возможность эфффективного обучения не только отдельным упражнениям, но и их объединению в фразы и комбинации упражнений.

Концептуальная сущность метода позных ориентиров движений состоит в том, что каждая предшествующая поза тела в выполняемом упражнении должна положительно влиять на биомеханику последующей позы тела, что позволяет выполнять упражнение без лишних двигательных перестроек с тем, чтобы не накапливать технические ошибки в процессе демонстрации упражнения или целой комбинации упражнений. В книге по теории вероятности [26], в разделе «Цепи Маркова» указано, что при сриксации на настоящем, последующее звено сохраняет память 0 предыдущем. «Вновь наступившее всегда расположено следовать за предыдущим... И подобно тому, как ладно расставлено все сущее, так и становящееся являет непростую последовательность, а некую восхитительную расположенность». Важное значение необходимо придавать разработке и использованию в учебно-тренировочном процес- се специальных программ упражнений, формирующих умения и навыки выполнения узловых элементов спортивной техники в фазах упражнения. Эксперименты подтвердили целесообразность использования предложенной технологии эфрфективного обучения упражнениям на основе освоения узловых элементов спортивной техники в фазовой структуре упражнения.

Биологическая обратная связь как технология и современный метод обучения и управления двигательными действиями. Биологическая обратная связь (БОС) (англ. biofeedback обратная подача) в широком смысле означает отзыв, отклик, ответную реакцию на какое-либо действие или событие; технология и современный метод обучения и управления двигательными действиями (контроль, коррекция, регуляция). БОС - метод саморегуляции и технология, которые входят в практику спортивной тренировки. Ее следует понимать как замкнутый контур обратной связи [5, 8, 30, $34,38,40,41]$, позволяющий оперативно контролировать двигательные действия по каким-либо показателям (например, формировать равновесие тела по показателям стабилографии, предъявляемой на мониторе). На рисунке 4 представлен контур биологической обратной связи системы «Тренер-Спортсмен».

Успех любой биолого-педагогической программы обучения зависит от готовности занимающегося активно участвовать в процессе овладения упражнением [8, 30, 34, 36]. При этом основу содержательной обратной связи составляют зрительная, слуховая, тактильная, вестибулярная и другие сенсорные системы, а также различные сигналы - стимулы, позволяющие развивать навыки саморегуляции за счет тренировки и повышения

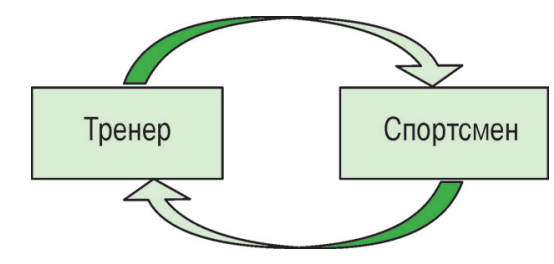

Рисунок 4 - Контур биологической обратной связи системы «Тренер-Спортсмен» лабильности, подвижности регуляторных механизмов ЦНС. Навыки саморегуляции строятся на приобретаемых в процессе обучения каналах связи, а также на вербально-моторной, зрительно-моторной, вестибуло-моторной, тактильно-моторной и других ассоциациях $[1,3,17,27,34,35]$. Рacсматриваются как элемент контроля повышения качества обучения и совершенствования техники спортивных упражнений в условиях учебнотренировочного процесса и соревновательной деятельности $[5,7,8,24]$, (рис. 5).

Все это предопределяет выверенные формулировки локальных целей и задач обучения, подбор дидактических принципов, методов, средств для формирования двигательных умений и навыков, форм занятий и способов организации занимающихся, элементов регламентации, контроля, коррекции на основе использования данных БOC.

Результативным алгоритмом, способствующим совершенствованию и последующей реализации БОС, служит фрункциональное педагогическое уравнение (ФПУ) как современная технология использования элементов дидактики в процессе обучения спортивным упражнениям различной координационной сложности. ФПУ детально раскрыто нами в предыдущих публикациях [5, 7, 24, 37]. Функциональное педагогическое уравнение тренер наполняет дидактическим материалом, исходя из главных и конкретных целей спортивной подготовки, а также задач обучения, заложенных в тренировочном занятии.

Алгоритм действия ФПУ. По планируемому результату обучения спортивному упражнению (в формуле это правая половина уравнения, выступающая как педагогическая директива - научить занимающегося стабильно выполнять упражнение (!), т.е. достичь планируемого результата), ведётся дидактическое программирование и структурирование содержания образования знаний, двигательных умений и навыков разучиваемого упражнения, т.е. подбирается наиболее адекватная и наиболее эффрективная структура и содержание элемен- 


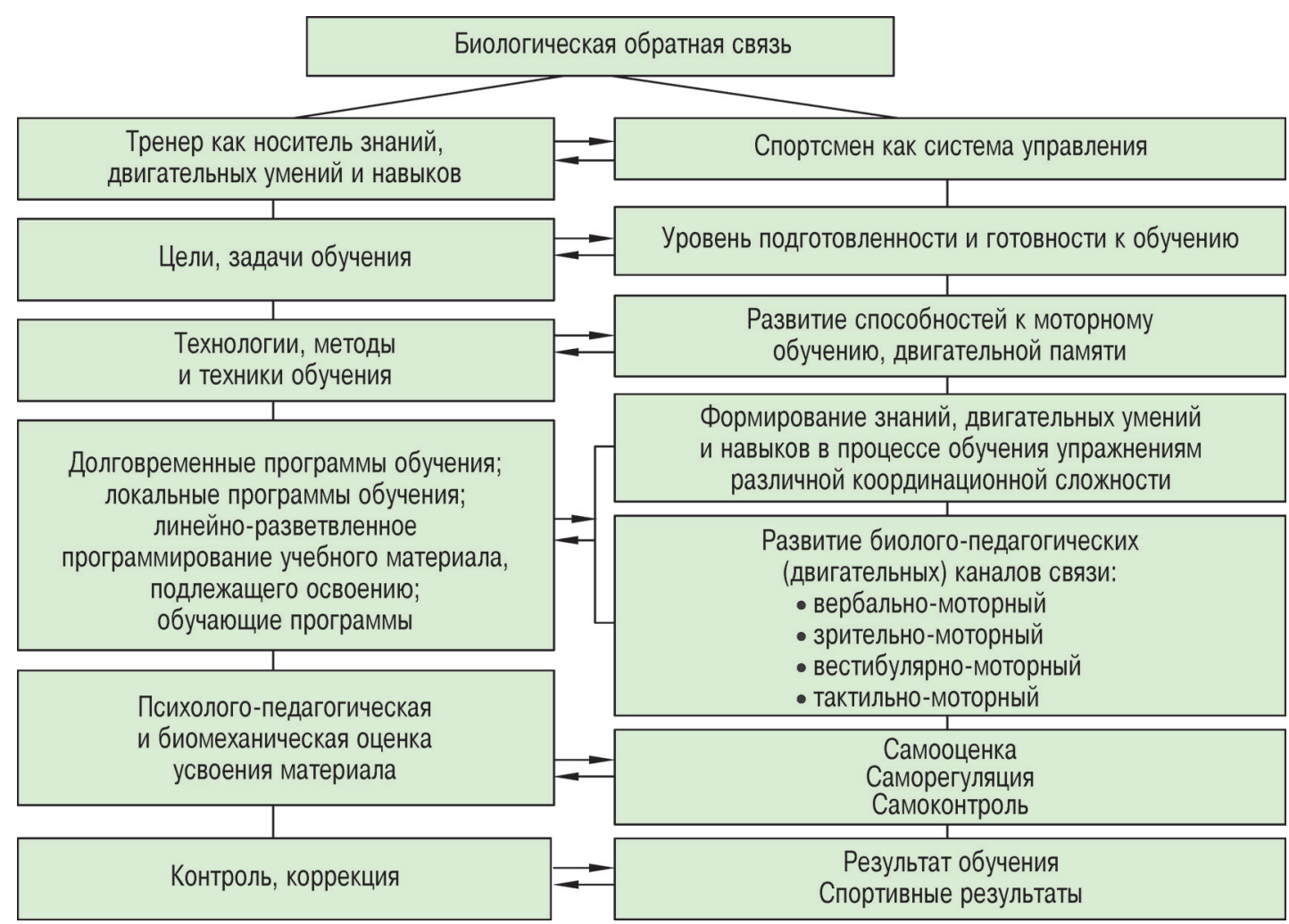

Рисунок 5- Методико-практическое использование компонентов биологической обратной связи в процессе формирования знаний, двигательных умений и навыков в процессе обучения спортивным упражнениям, сложным по координации

тов дидактики (в фрормуле - это левая половина уравнения). Таким образом формируется готовность занимающегося активно участвовать в процессе овладения упражнениями. ФПУ решаются успешно, если средства обучения реализуются на основе использования биомеханических показателей спортивной техники упражнений и построенных на этой основе алгоритмов линейно-разветвлённого программирования дидактического материала.

Достигается соотношение показателей эфрфективности подбора элементов дидактики с планируемыми процессами обучения. Так, формирование двигательных представлений - начальное обучение спортивному упражнению осуществляется в том случае, когда занимающийся владеет определенным доступным арсеналом движений - упражнений в рамках решаемых двигательных задач, хорошо ориентируется в пространстве, во времени, знает какие усилия необходимо приложить, чтобы выполнить двигательное действие; сознательно контролирует выполнение двигательного задания в благоприятной обстанов- ке: помощь, страховка, облегченные условия. Занимающийся копирует увиденное, двигательно представляет пространство, в котором выполняется упражнение, учится оценивать время выполнения деталей техники, фаз и упражнения в целом, проявлять мышечные усилия, необходимые для выполнения задания (оперативное научение). Оперативное научение - это установление ассоциативной связи между поведением (действием) и следствием этого поведения (действия). «Последствия поведения могут играть роль обратной связи для организма. В этом случае они изменяют вероятность осуществления поведения, породившего их» [28, 29].

Продолжается учебная работа по приобретению навыков стыковки фраз разучиваемого упражнения, а также динамических соединений двух и более упражнений. Многократное осмысленное выполнение упражнения по частям или в целом, его узловых элементов спортивной техники позволяет формировать гибкий двигательный навык, дающий основу для разучивания новых упражнений. Фор- мируется двигательная и психологическая совместимость между партнёрами по группе. Активизируется творческая поисковая деятельность тренера и занимающихся, устанавливаются дополнительные контуры вербального и моторного их взаимодействия, что развивает БОС и совершенствует процесс обучения. Преимущественно реализуются принципы: научности, индивидуализации, сопряжённого воздействия, трудности, совместимости; правила обучения: опережающая сложность, способности к обучению не одинаковы, в обучении следуй от легкого к трудному, а при необходимости и от трудного к лёгкому, от простого к сложному и от сложного к простому, интенсивность, напряжённость, оптимальность, стабильность, надёжность; методы обучения: практический, проблемный, моделирования, программирования, группового обучения, соревновательный; методы организации занимающихся: индивидуальный, парный, групповой, посменный, игровой; средства обучения: упражнения соревновательных программ (классификационных, про- 
извольных, финнальных), учебные задания из арсеналов программ подготовительных, подводящих, имитационных упражнений, технические средства, тренажеры и тренажёрные комплексы.

Трансферное обучение. Трансфер (англ. transfer - переносить, перемещать). В своей книге П. Фресс, Ж. Пиаже [35] уделили большое внимание исследованию переноса сенсомоторных навыков. Они указывают, что возможен перенос как между рецепторами, принадлежащими к одной и той же сенсорной модальности (интрасенсорный перенос), так и между рецепторами различной модальности (интерсенсорный перенос). Ученые пишут, что упражнение и тренировка способствуют облегчению различных видов перцептивной деятельности, простых и сложных. Перенос двигательного навыка в процессе обучения фризическим и спортивным упражнениям получил теоретикопрактическое развитие в трудах многих исследовтелей [8, 9, 15, 24, 33, 37]. В частности, некоторые из них [24] исследовали эффрект моторного обучения гимнастическим упражнениям на основе реализации трансфрерной технологии и пришли к положительным выводам.

Перенос в обучении выражается во влиянии некоторого аспекта предыдущего опыта на последующую деятельность. Чаще акцент делался на изучение отрицательного переноса двигательного навыка. Проблема была крайне актуальна в шестидесятых-восьмидесятых годах прошлого столетия. Наряду с эфффективными результатами обучения и подготовки возникали дискуссии, например, по вопросу «Можно ли учить в одном тренировочном занятии сальто назад в группировке (узловой элемент техники - прыжок вверх) и перевороту назад (узловой элемент техники - прыжок назад). Высказывались мнения о том, что различные двигательные действия, объединённые необходимыми педагогическими задачами, будут затруднять процесс фрормирования у занимающегося двигательных умений и навыков, фактически плодить технические ошибки при овладении спортивными упражнениями. Возникали и другие вопросы и мнения. В принципе, многие положения дискуссий были актуальны до тех пор, пока не была разработана теория и методика базовой подготовки, предусматривающая создание у занимающегося арсенала движений - упражнений, когда спортсмен хорошо понимает и умеет выполнять упражнения одного профиля, упражнения различных просрилей, успешно справляется с предложенными для выполнения подготовительными, подводящими, имитационными упражнениями, содержащими необходимые пространственные, временные и силовые компоненты двигательных действий; более совершенно стал строиться процесс многолетний спортивной подготовки. Важное значение в процессе реализации современной технологии трансферного обучения спортивным упражнениям имеет характер решаемых задач, их взаимовлияние и взаимозависимость. В процессе обучения выделена и исследована технология трансфрера обучения по вертикали и технология трансфера обучения по горизонтали [5, 24, 37, 39].

Технология трансфрера обучения по вертикали - алгоритмическая последовательность овладения упражнениями возрастающей трудности. Например, на ковре для вольных упражнений спортсменка овладела пируэтом, далее следует овладение полутора пируэтами, двойным пируэтом, двумя с половиной пируэтами, тройным пируэтом (упражнения одного профиля). Возможно последует овладение упражнениями разных профилей и их демонстрация в соревнованиях. Технология трансфера обучения по горизонтали - выученное упражнение на одном гимнастическом снаряде вводится в упражнения на других гимнастических снарядах. Например, пируэт, который освоен на вольных упражнениях, спортсменка выполняет на брусьях разной высоты - соскок-сальто пируэт; на бревне - соскок-рондат-сальто пируэт, на опорном прыжке - Юрченко-сальто назад прогнувшись с поворотом на $360^{\circ}$ (пируэт). При этом необходима своего рода частная методика обуче- ния, предусматривающая использование элементов «подгонки» деталей техники к новым условиям выполнения упражнения, или связки упражнений; необходимы новые стандарты исполнительского мастерства, новая ритмика системы «спортсменка-гимнастический снаряд». С позиции современного спорта высших достижений можно говорить о том, что проблема обучения оригинальным способом транссрормируется в новые технологии двигательного взаимодействия спортивных упражнений различных профилей, их биомеханически целесообразной «стыковки» в различных видах спорта: биомеханическая структура упражнений прыгунов на акробатической дорожке и гимнастов на вольных упражнениях; прыгунов на батуте, прыгунов в воду и занимающихся лыжной акробатикой.

В связи с обилием и разнообразием форм движений в видах спорта со сложной координационной структурой двигательных действий попрежнему приходится учитывать возможности переноса эффекта от овладения одним упражнением на вновь изучаемое. В зависимости от степени общности или различий в структуре движений изучаемых упражнений остаются «педагогические и практические следы» от возможных положительных или отрицательных переносов эфффекта от ранее изученного упражнения на последующее. С учётом особенностей переноса двигательного навыка определяются последовательность, варианты обучения, подбираются учебные задания с тем, чтобы освоение одних упражнений благоприятно сказывалось на освоении других.

Практика показывает, что противоречия в движениях, «лавинно» нарастающие ошибки в технике упражнений встречаются в тех случаях, когда у занимающихся не сформирован навык управления движениями, который создаётся упражнениями общеразвивающегося просриля, отсутствует надлежащая «школа движений», не высокий уровень базовой и специальной технической подготовленности, когда проявляется торопливость в обучении и даже эксплуатируются при- 
родные качества юных спортсменов Чтобы избежать этих сложностей, необходимо следовать в русле рекомендуемых нами долговременных программ обучения, осуществлять регламентацию, контроль и коррекцию процесса обучения [5, 7, 39].

В связи с использованием технических средств обучения, включая и современную научную аппаратуру для контроля качества обучения спортивной технике, а также логично подобранных учебных заданий, происходит энергосбережение ресурсов спортсмена, приобретается психическая устойчивость при выполнении упражнений, осмысленное отношение к процессу и качеству обучения, логично регулируется количество повторений упражнений, снижается травматизм. Результат обучения упражнению становится элементом более совершенной системы биологической обратной связи в структуре спортивной подготовки.

Долговременная программа управления обучением спортивным упражнениям. Разработана и прошла экспериментальную проверку долговременная программа управления обучением (ДПУО) упражнениям, сложным по координации, и ее логикоструктурная схема. ДПУО упражнениям «школы движений», базового уровня, произвольных и фринальных программ, а также развития фризических качеств в сопряжении с показателями технической подготовленности разработана на основе алгоритмов взаимодействия главной цели и конкретных целей (локальные программы обучения) многолетней подготовки спортсменов [5, 7, 39].

Главная цель: экстраполяция развития структурных групп спортивных упражнений и их трудности в структуре многолетней подготовки; разработка долговременных программ обучения базовым упражнениям, а также упражнениям возрастающей трудности и высшей трудности, исходя из просрилей структурных групп упражнений. Результат реализации главной цели - стабильное выступление в спортивных соревнованиях различного уровня, выполнение четверного сальто назад в группировке, выполне- ние норматива мастера спорта международного класса.

Конкретные цели: обучение спортивным упражнениям, соответствующим требованиям программ этапов многолетней подготовки, овладение подготовительными, подводящими вспомогательными, имитационными упражнениями, а также упражнениями соревновательных программ; сопряжение видов подготовки и подготовленности занимающихся (локальные и обучающие программы), исходя из профилей структурных групп упражнений; выполнение нормативов соответствующего спортивного раз ряда.

Дидактической основой предложенной ДПУО служат технологии с элементами биологической обратной связи формирования двигательных представлений, начального, углубленного обучения упражнениям, а также совершенствования системь движений в структуре многолетней спортивной подготовки, с учетом информации о качествах личности свойствах нервной системы занимающихся, а также полидисциплинарных особенностей развития двигательных умений и двигательных навыков (биологических, биомеханических, психолого-педагогических).

Дидактическая структура ДПуо разрабатывается с учетом индивидуального уровня ффизической, технической подготовленности занимающе гося, трудности спортивных упражнений, подлежащих усвоению; адекватности и взаимозависимости главной цели и конкретных целей, задач обучения; специфичных дидактических принципов, методов, средств, элементов регламентации, контроля и коррекции процесса обучения. Тренер в процессе обучения конкретному спортивному упражнению (реализуя конкретную цель), подбирает методы и средства (локальная и обучающая программы), исходя из главной цели спортивной подготовки. Работает по схеме: «в обучении спортивным упражнениям следует идти от главной цели к конкретной цели и снова к главной цели», т.е. держать под контролем весь процесс обучения, рассчитанный на перспективу $[5,12]$.
Содержание классификационных, произвольных и сринальных программ, а также программ обучения и тренировочных занятий структурнофункционально увязываются между собой, реализуются на протяжении определенного периода спортивной подготовки, с учетом изменений в Правилах соревнований. При этом программы обучения совершенствуются, трансформируются под влиянием тенденций развития видов спорта, проектирования и конструирования новых упражнений, индивидуального стиля спортивной техники исполнителей упражнений, новых условий обучения и проведения тренировочных занятий. Профрессор Ю. К. Гавердовский [9] пишет, что в отличие от видов спорта типа легкой атлетики и всевозможных локомоций, игр, единоборств, штанги, технических видов и др., технико-эстетические виды спорта на протяжении всей карьеры спортсмена требуют постоянного обновления и качественного усложнения соревновательной программы. До 80 \% всего времени занятий (не считая соревнований) гимнасты, акробаты, сригуристы тратят на освоение и совершенствование именно техники упражнений, т.е. на обучение и технически ориентированную тренировку.

В статье [7] детально раскрыта Долговременная программа обучения (а также ее локальные и целевые обучающие программы) опорным прыжкам типа Юрченко, ее элементы и примерные активные периоды их реализации, логико-структурная схема прохождения учебного материала, подлежащего освоению с учетом методического взаимодействия главной цели и конкретных целей на этапе специализированной базовой подготовки

Линейно-разветвленное программирование освоения учебного материала. Технология обучения двигательным действиям представляет собой процедуру передачи знаний, умений и навыков от тренера к ученику, построенную в расчете на получение определенного качественного результата. С современной точки зрения процесс обучения представляет собой сложную динамическую систему, нуждающуюся в четко регламентиро- 

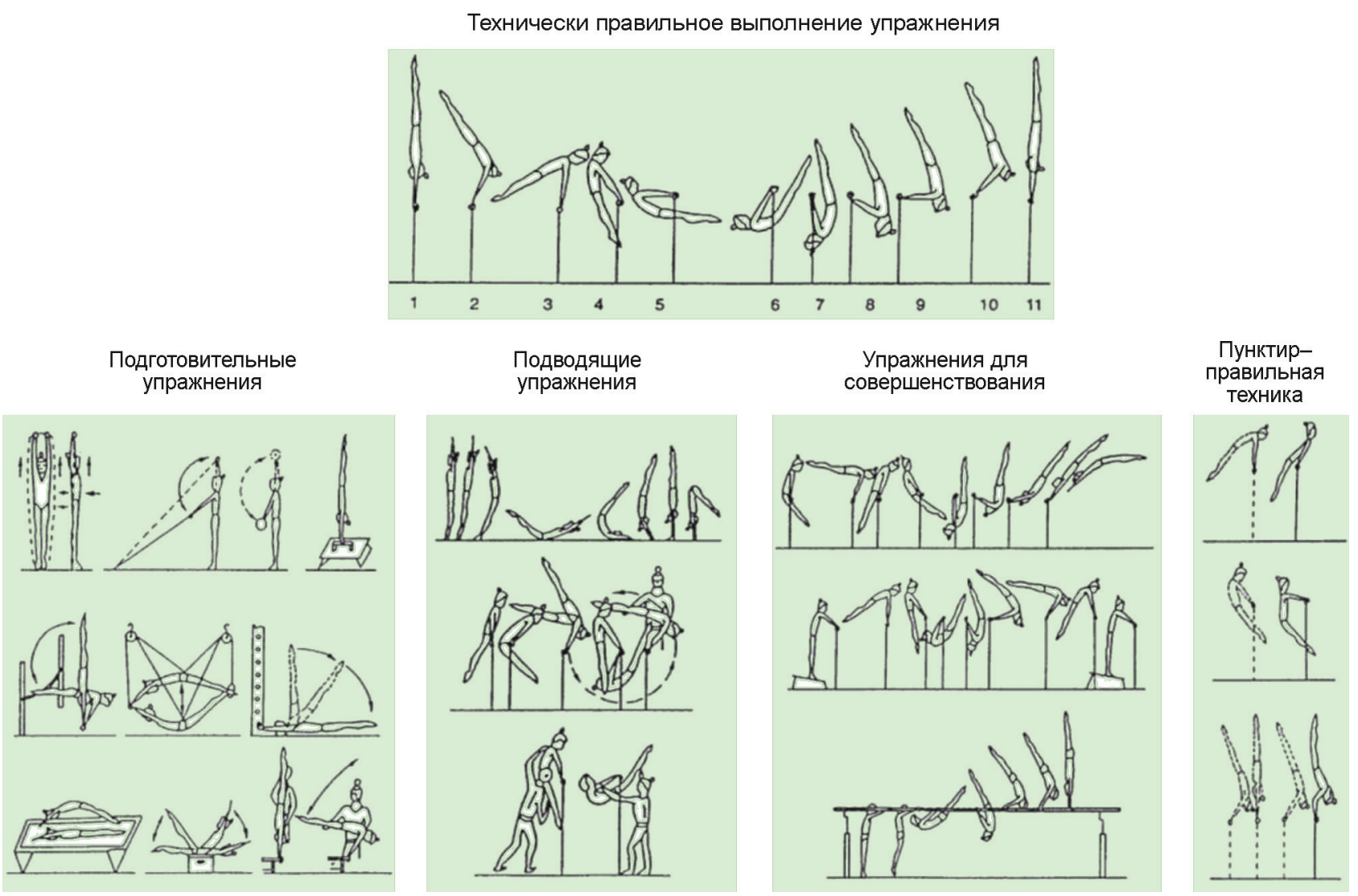

Рисунок 6 - Линейно-разветвлённое программирование учебного материала при обучении обороту назад в стойку на брусьях разной высоты [37].

ванном управлении. Важным технологическим элементом такой системь является моторное обучение и процедурная память, а также программноуправляемое или программированное обучение. Моторное обучение - процесс улучшения формирования двигательных навыков, точности и координации движений [8, 16, 19, 24, 29 , 36]. Этот тип обучения необходим для развития сложности упражнений в процессе спортивной подготовки (рис. 6). Важное значение в процессе эффрективной реализации моторного обучения играет процедурная память о том, как выполнять различные двигательные действия [16, 24, 28, 29, 35]. Она руководит процессами, которые выполняют спортсмены, и очень часто остается ниже уровня осознания. Процедурная память автоматически «подгружается» и используется для выполнения интегрированных сложных упражнений. Их основой является повторение двигательных действий, отличающих (различающих) когнитивные и моторные навыки последовательности двигательных дей- ствий снова и снова, пока нейросистема не «свяжется» нужным образом [1, $3,8,21,33,34,40,41]$.

Линейно-разветвленное пошаговое программирование учебного материала, алгоритмизация содержания образования знаний, двигательных умений и навыков в процессе обучения спортивным упражнениям различной координационной сложности при реализации в тренировочных занятиях элементов дидактики - это технология обучения, наиболее полно охватывающая исследовательский и педагогический процессы, способствующие эффективному освоению базовых, трудных и высокой трудности упражнений. В этом случае необходимо ориентироваться на теорию опережающего обучения [13], в основу которой заложены принцип ведущей роли теоретических знаний, принцип осознания обучаемым собственного учения (личностная саморегуляция - БОС), принцип обучения на высоком уровне трудности [4]. Устанавливается достоверный факт использования в системе спор- тивной подготовки современной макрометодики обучения упражнениям, сложным по координации [7].

Макрометодика представляет динамичную систему теоретических и учебно-методических материалов, реализуемых в процессе спортивной подготовки. Макро (с греч. накро́ , но́крос - макрос) - начальная часть слова, указывающая на большие размеры или значительную величину, на совокупность чего-либо. Методика - готовый «рецепт», алгоритм, процедура для проведения какихлибо нацеленных действий; в образовании - описание конкретных приемов, способов, техник педагогической деятельности. Структурно макрометодика представляет функциональную совокупность элементов долговременных, локальных программ обучения упражнениям «школы движений», базового уровня, специализации, соревновательных упражнений путем интеграции двигательной, биологической, биомеханической, дидактической, технологической, функциональной структур спортивных упраж- 
нений различной координационной сложности.

Таким образом, поставленная цель - разработать и обосновать отдельные актуальные технологии управления процессом обучения спортивным упражнениям со сложной координационной структурой движений как концепцию повышения уровня технической подготовки и подготовленности спортсменов в основном решена. Концепция рассматривается как направление развития технологий и идея теоретико-практического поиска и внедрения в учебно-тренировочный процесс актуальных элементов дидактики построения алгоритмов управления процессом обучения на основе полидисциплинарного формирования знаний, двигательных умений и навыков для повышения технической подготовленности спортсменов.

\section{Выводы:}

1. Анализ научно-методической литературы, опыта практической работы тренеров, а также результатов выступления спортсменов в соревнованиях позволили установить ряд недостаточно решенных вопросов теории и методики обучения в связи с активным ростом трудности соревновательных программ и повышением требований к уровню исполнительского мастерства занимающихся видами спорта, сложными по координации. Проблема состоит в том, что специальной литературы недостаточно, опыт профессиональных тренеров не всегда доступен для анализа и использования; в учебно-тренировочных занятиях присутствует фракт форсированной технической подготовки спортсменов, особенно юных.

2. Изучены и реализованы следующие актуальные технологии управления процессом обучения: структурный состав спортивного упражнения, подлежащего освоению; полидисциплинарное формирование двигательных представлений, двигательных умений и навыков; узловые элементы спортивной техники как позные ориентиры движений в фазовой структуре упражнения; биологическая обратная связь как технология и современный метод обучения и управления двигательными действиями; трансферное обучение; долговременная программа управления обучением спортивным упражнениям; линейноразветвленное программирование освоения учебного материала.

3. Развитие технологий управления процессом обучения двигательным действиям строится на знании учете и использовании биологических механизмов, управляющих иррадиацией, концентрацией и стабилизацией процессов возбуждения и торможения в центральной нервной системе.

4. Технологии управления процессом обучения позволяют достичь стабильности и надежности спортивной техники выполняемых упражнений, возможностью проектирования и конструирования новых двигательных действий на основе знаний о структурном составе спортивного упражнения.

5. Разработанные пошаговые алгоритмы линейно-разветвленного программирования учебного материала подлежащего освоению, составляют методологическую основу технологий эфффективного управления процессом обучения спортивным упражнениям сложным по координации.

Конфликт интересов. Автор заявляет, что отсутствует какой-либо конфрликт интересов.

\section{ЛИТЕРАТУРА}

1. Анохин ПК. Очерки по фризиологии функциональных систем. Москва: Медицина 1975. 448 c.

2. Берг АИ. Состояние и перспективы программированного обучения. Москва: Знание 1966. 27 c.

3. Бернштейн НА. 0 ловкости и е разви тии. Москва: Физкультура и спорт; 1991. 287 с

4. Болобан ВН. Принцип трудности. Обу чение в спортиной акробатике. Киев: Здоров'я 1986. 30-7.

5. Болобан В. Долговременные программы обучения упражнениям спортивной акроба тики. Наука в олимпийском спорте, 2011; 1-2: 75-87.

6. Болобан В, Потоп В. Биомеханическая характеристика узловых элементов спортив ной техники упражнений на снарядах женско го гимнастического многоборья. Наука в олим пийском спорте. 2014; 1: 44-9.

7. Болобан В, Потоп В. Основы макромето дики обучения спортивным упражнениям (на материале женских видов спортивной гимна стики). Наука в олимпийском спорте. 2015; 4 $55-67$.

8. Гавердовский ЮК. Обучение спортивным упражнениям. Биомеханика. Методология. Ди дактика. Москва: Физкультура и спорт; 2007. 912 c.
9. Гавердовский ЮК, Смолевский ВМ. Теория и методика спортивной гимнастики. Москва: Советский спорт; 2014. Т. 1. 368 с. Т. 2. $231 \mathrm{c}$

10. Гальперин ПЯ. 0 формировании умственных действий и понятий. Культурно-историческая психология. 2010; 3: 111-4.

11. Гамалий ВВ. Теоретико-методические основы моделирования техники двигательных действий в спорте. Киев: Полиграфрсервис; 2013. $300 \mathrm{c}$

12. Жмарев НВ. Тренировка гребцов. Киев: Здоров'я; 1976. 124 с.

13. Занков ЛВ. Дидактика и жизнь. Москва: Просвещение; 1968. 176 с.

14. Коменский ЯА. Великая дидактика Педагогическое наследие: ЯА. Коменский Д. Локк, Ж.-Ж. Руссо, И.Г. Песталоцци. Сост. В.М. Кларин, А.Н. Джуринский. Москва: Педагогика; 1989. 416 с

15. Коренберг ВБ. Двигательный навык, двигательная задача. Гимнастика. Москва: Физкультура и спорт. 1986; 1: 41-4.

16. Краудер Н. О различиях между линейным и разветвленным программированием. Программированное обучение за рубежом. Москва: Высшая школа, 1968; 58-67.

17. Крестовников АН. Очерки по физиологии фризических упражнений. Москва: Физкультура и спорт; 1951. 531 с.

18. Леонтьев АН. Деятельность. Сознание. Личность. Москва: Политиздат; 1977. 303 с.

19. Литвиненко ЮВ. Регуляція пози спортсменів у складних умовах статодинамічної стійкості тіла: монографія. Луцьк: Вежа-Друк; 2018. 324 c.

20. Мазниченко ВД. Двигательные навыки в гимнастике. Москва: Физкультура и спорт; 1959. $136 \mathrm{C}$.

21. Николас Ф. Уимбс, Эми Дж. Бастиан, Пабло А. Челник. Моторные навыки укрепляются за счет повторной консолидации. Current Biology. 2016. 26 (3): 338-343.

22. Ope 0. Приглашение в теорию чисел. Москва: Наука; 1980. 128 с.

23. Платонов ВН. Периодизация спортивной тренировки. Общая теория и ее практическое применение. Киев: Олимпийская литератуpa; 2013. 624 c.

24. Потоп В, Григоре В, Маринеску С. Моторное обучение гимнастическим упражнениям на основе трансферной технологи. Наука в олимпийском спорте. 2012; 1: 47-57.

25. Радионенко А, Говердовский В. Базовая подготовка гимнастов на коне: техника выполнения скрещений и кругов плечевым поясом. Наука в олимпийском спорте, 2012; 1: 93-7.

26. Ревюз Д. Цепи Маркова. Москва: РРФИ; 1997. 432 с

27. Сеченов ИМ. Рефлексы головного м0зга. Москва: АСТ, Времена 2; 2014. 352 с.

28. Скиннер БФ. Наука об учении и искусство обучения. Программированное обучение за рубежом. Москва: Высшая школа; 1968. $32-46$.

29. Скиннер БФ. Оперативное поведение. История зарубежной психологии. Москва: Наука; 1986. 60-95.

30. Слобунов СМ. Исследование соотношений когнитивного и исполнительского компонентов двигательного действия [автореферат]. Ленинград. 1977. 18 с.

31. Смолевский ВМ, Гавердовский ЮК. Спортивная гимнастика. Киев: Олимпийская лит. 1999. 462 с. 
32. Сучилин Н. Техническая структура гимнастических упражнений. Наука в олимпийском спорте, 2012. 1: 84-9.

33. Сучилин НГ, Аркаев ЛЯ. Базовые навыки и стратегические элементы. Гимнастика, теория и практика: Методическое приложение к журналу «Гимнастика». Москва: Советский спорт; 2010. Вып. 1: 67-73.

34. Штарк МБ. Биоуправление - 4. Теория и практика. Новосибирск: ЦЭРИС; 2002. 350 с.

35. Фресс П., Пиаже Ж. Экспериментальная психология. Москва: Прогресс; 1973. 344 с

36. Худолій ОМ, Єрмаков СС. Закономірності процесу навчання юних гімнастів. Теорія та методика фізичного виховання; Харків. 2015: 3-18.

37. Boloban V. Sensorimotor as the basis of technical preparation coordination. Science in Olympic Sport. 2019; 4: 75-84

38. Niźnikowski T. Efektywnoś uczenia się złoźonych czynności ruchowych a rodzaj informacji zwrotnej. Monografie i Oprasowania - Biala Podlaska: WWFS; 2013. nr. 18. 156 p.

39. Potop V, Boloban V, Triboi V, Goraschenco A. Correlative analysis of the biomechanical characteristics and performances achieved by junio gymnasts in balance beam events. Discobolul Physical Education, Sport and Kinetotherapy, Journal 2017; Vol. XIII no. 2(48): 30-35

40. Scheeler MC, Ruhl K, McAfee J. Providing performance feedback to teachers: a review. Teacher Education and Special Education, 2004; 27: 396-407.

41. Schmidt RA, Wulf G. Continuous concurrent feedback degrades skill learning: Implications for training and simulation. Human Factors, 1997 39: 509-25.

\section{LITERATURE}

1. Anokhin PK. Essays on functional system physiology. Moscow: Meditsina; 1975. 448 p.

2.Berg Al. State and prospects of programmed education. Moscow: Znaniye; 1966. 27 p.

3. Bernstein NA. On agility and its development. Moscow: Fizkultura i sport; 1991. 287 p.

4. Boloban VN. Principle of difficulty. Teaching in sports acrobatics. Kiev: Zdorovia; 1986. 30-7.

5. Boloban V. Long-term progtams for teaching sports acrobatics exercises. Nauka v Olimpiyskom sporte, 2011; 1-2: 75-87.

6. Boloban V, Potop V. Biomechanical characteristics of the key elements of sports technique of exercises on the apparatus of the female all-around. Nauka v Olimpiyskom sporte. 2014; 1: 44-9

7. Boloban V, Potop V. The basics of the macro methodology of teaching sports exercises (based on the material of female types of artistic gymnastics). Nauka v Olimpiyskom sporte. 2015; 4: $55-67$.

8. Gaverdovsky YK. Teaching sports exercises. Biomechanics. Methodology. Didactics. Moscow: Fizkultura i sport; 2007. 912 p. and methods of artistic gymnastics. Moscow: Sovetsky sport; 2014. Vol. 1. 368 p. Vol. 2. 231 p.

10. Galperin PY. On mental action and notion formation. Kulturno-istoricheskaya psikhologiya. 2010; 3: 111-4.

11. Gamaliy VV. Theoretico-methodical bases of motor action technique modeling in sport. Kiev: Poligrafservis; 2013. 300 p.

12. Zhmarev NV. Training of rowers. Kiev: Zdorovia; 1976. 124 p.

13. Zankov LV. Didactics and life. Moscow: Prosveshcheniye; 1968. 176 p.

14. Komensky YA. Great didactics. Pedagogical heritage: YA. Komensky, D. Lock, J.-J. Russo IG. Pestalocci. Comp. V.M. Klarin, A.N. Dzhurinsky. Moscow: Pedagogika; 1989. 416 p

15. Korenberg VB. Motor skill, motor task Gymnastics. Moscow: Fizkultura i sport. 1986; 1 41-4.

16. Krauder N. On differences between linea and branched programing. Programed learning abroad. Moscow: Vysshaya shkola, 1968; 58-67.

17. Krestovnikov AN. Essays on physical exercise physiology. Moscow: Fizkultura i sport; 1951 $531 \mathrm{p}$.

18. Leontyev AN. Activity. Consciousness Personality. Moscow: Politizdat; 1977. 303 p.

19. Lytvynenko IV. Athlete posture regulation ity: monograph. Lutsk: Vezha-Druk; 2018. 324 p.

20. Maznichenko VD. Motor skills in gymnastics. Moscow: Fizkultura i sport; 1959. 136 p.

21. Nicolas F. Wimbs, Emi J. Bastian, P.A. peated consolidation. Current Biology. 2016. 26 (3): 338-343. Moscow: Nauka; 1980. 128 p.

23. Platonov VN. Sports training periodization. General theory and its practical applications Kiev: Olimpiyskaya literatura; 2013. 624 p.

24. Potop V, Grigore V, Marinesku S. Moto training gymnastic exercises on the basis of trans fer technology. Nauka v Olimpiyskom sporte. 2012; 1: 47-57.

25. Radionenko A, Goverdovsky V. Basic preparation of gymnasts: technique for performing crosses and circles with the shoulder girdle. Nauka v Olimpiyskom sporte, 2012; 1: 93-7.

26. Revies D. Markov's chains. Moscow: RRFI 1997. $432 \mathrm{p}$.
9. Gaverdovsky YK, Smolevsky VM. Theory in complex conditions of body statodynamic stabilChelnik. Motor skills are strengthen through re-

22. Ore 0 . An invitation to number theory

27. Sechenov IM. Brain reflexes. Moscow: AST, Vremena 2; 2014. 352 p.

28. Skinner BF. The science of learning and the art of teaching. Programmed training abroad Moscow: Vysshaya shkola; 1968. 32-46.

29. Skinner BF. Operative behavior. Foreign psychology history. Moscow: Nauka; 1986. 60-95

30. Slobunov SM. Study of correlations of motor action cognitive and performing compo nents [abstract]. Leningrad. 1977. 18 p

31. Smolevsky VM, Gaverdovsky YK. Artistic gymnastics. Kiev: Olimpiyskaya literatura. 1999 $462 \mathrm{p}$

32. Suchilin N. Gymnastic exercise technica structure. Nauka v Olimpiyskom sporte, 2012. 1 84-9.

33. Suchilin NG, Arkaev LY. Basic skills and strategic elements. Gymnastics, theory and practice. Sovetsky sport; 2010. Iss. 1: 67-73.

34. Shtark MB. Biomanagement -4 . Teory and practice. Novosibirsk: TSERIS; 2002. 350 p.

35. Fress P., Piazhe J. Experimental psychology. Moscow: Progress; 1973. 344 p.

36. Khudolii OM, Iermakov S. Regularities of the process of teaching young gymnasts. Teoriia ta metodyka fizvykhovannia; Kharkiv. 2015: 3-18.

37. Boloban V. Sensorimotor as the basis of technical preparation coordination. Science in Olympic Sport. 2019; 4: 75-84

38. Niźnikowski T. Efektywnoś uczenia się złoźonych czynności ruchowych a rodzaj informacji zwrotnej. Monografie i Oprasowania - Biala Podlaska: WWFS; 2013. nr. 18. 156 p.

39. Potop V, Boloban V, Triboi V, Goraschenco A. Correlative analysis of the biomechanical characteristics and performances achieved by junior gymnasts in balance beam events. Discobolul Physical Education, Sport and Kinetotherapy, Journal 2017; Vol. XIII no. 2(48): 30-35.

40. Scheeler MC, Ruhl K, McAfee J. Providing performance feedback to teachers: a review. Teacher Education and Special Education, 2004 27: 396-407.

41. Schmidt RA, Wulf G. Continuous concurrent feedback degrades skill learning: Implications for training and simulation. Human Factors, 1997 39: 509-25.

Передруковано з: Наука в олимпийском спорте; 2017, 4, доповнено

Надійшла 23.03.2020

\section{ІНФОРМАЦІЯ ПРО АВТОРА}

Болобан Віктор Миколайович https://orcid.org / 0000- 0001-9119-0695, wboloban@ukr.net Бердянський державний педагогічний університет Запорізька обл., м. Бердянськ, вул. Шмідта, 4

\section{INFORMATION ABOUT THE AUTHOR}

Boloban Viktor https://orcid.org / 0000-0001-9119-0695, wboloban@ukr.net

Berdyansk State Pedagogical University

Shmidta st. 4, city Berdyansk, Zaporozje Region. 